\title{
PEMBINAAN AQIDAH DI PANTI ASUHAN MINORITAS MUSLIM
}

\author{
Wahyudin B, Witanti Kasan, Ismail Suardi Wekke \\ Sekolah Tinggi Agama Islam Negeri (STAIN) Sorong \\ Email: iswekke@gmail.com
}

\begin{abstract}
Disampaikan Dalam
International Postgraduate Research Conference

Institut Agama Islam Negeri (IAIN) Manado
\end{abstract}

12-13 November 2016

\section{PENDAHULUAN}

Pengasuhan alternatif merupakan pengasuhan berbasis keluarga pengganti atau berbasis lembaga kesejahteraan sosial anak dilaksanakan oleh pihak - pihak diluar keluarga inti atau kerabat anak. Pengasuhan alternatif dapat di lakukan melalui sistem orang tua asuh (fostering), wali (quardian ship) atau pengangkatan anak dan pada pilihan terakhir adalah pengasuhan berbasis residential (lembaga kesejahteraan Sosial Anak/panti asuhan). Tujuan dari pengasuhan alternatif melalui panti asuhan harus diprioritaskan untuk menyediakan lingkungan yang dapat memenuhi kebutuhan kasih sayang anak, kelekatan (attachment), dan permanensi melalui keluarga pengganti.

Salah satu lembaga yang peka sosial terhadap ketelantaran anak yatim piatu muslim papua adalah panti asuhan putera puteri Papua Muslim yang dibentuk melalui yayasan Al Muhajirin, sebagai bentuk respon sosial ketika situasi ketelantaran anak yatim piatu dan anak anak dari keluarga kurang mampu maupun dari keluarga yang tidak 
harmonis, dikhawatirkan mereka akan mengalami masa- masa sulit seperti frustasi, merasa sendiri dan tidak ada yang peduli sehingga meng ancam kehidupan dimasa depannya, hal inilah yang mendasari didirikannya panti asuhan putera puteri papua muslim sebagai wujud keprihatinan dan kepedulian masyarakat muslim sekitar terhadap nasib anak yatim kususnya muslim. Papua Barat merupakan cerminan harmoni dengan perjumpaan antar umat beragama (Wekke, 2017).

Sementara Kumalasari \& Ahyani (2012), Hartati \& Respati (2012), Suryo (2010) masing-masing memublikasikan pada tema-tema sebatas dukungan sosial, kompetensi interpersonal, dan gaya kepemimpinan (Irwin, \& Bradshaw, 2011). Ketiga penelitian tersebut tidak secara khusus mengkaji hubungan panti asuhan dengan pembinaan akhlak. Adapun kajian minoritas muslim sebatas pada sasi (Wekke, 2015), tradisi pesantren (Wekke, 2015b), identitas muslim (Wekke, 2012; Cintas, Gosse, \& Vatteville, 2013), masjid dalam ekspresi keberagamaan (Wekke, 2013; McCormack, Brinkley-Rubinstein, \& Craven, 2014). Kajian-kajian tersebut masih sebatas pada disiplin tertentu. Sementara secara khusus identifikasi panti asuhan dieksplorasi dalam kaitan dengan kelembagan pendidikan Islam (Wekke, Siddin, \& Kasop, 2017). Sehingga, sebuah diperlukan kajian untuk mengidentifikasi panti asuhan dalam melaksanakan pembinaan pendidikan Islam di Tanah Papua terhadap muslim minoritas.

\section{SELAYANG PANDANG PANTI ASUHAN PUTERA PUTERI PAPUA MUSLIM}

Panti asuhan putera puteri papua muslim didirikan pada tanggal 22 Oktober tahun 2000 oleh yayasan Al Muhajirin yang saat ini telah beralih yayasan menjadi yayasan Al Hijrah, penggagasnya adalah Alm. Abdul Munyasih. Gosita (1998) menyatakan bahwa usaha- 
usaha kesejahteraan sosial ialah semua upaya program dan kegiatan yang ditujukan untuk mewujudkan, memelihara, memulihkan dan mengembangkan kesejahteraan sosial.

Sejalan dengan gambaran awal didirikan adalah bentuk keprihatinan beliau terhadap sesama muslim dari daerah Bintuni yang masyarakatnya banyak berdomisili di derah kabupaten Aimas, kehidupan keseharian mereka sangat memperihatinkan, untuk menafkahi keluarga dengan kebutuhan yang pantas sangat sulit diberikan, pendidikan anak terbengkalai, pembinaan agama pun sulit diberikan dengan alasan waktu yang habis terpakai untuk bekerja sebagai buruh atau pemahaman agama orangtua yang minim berbagai macam alasan masalah yang dihadapi terlebih bagi anak yang telah ditinggal orang tuanya rentan mengalami hal yang lebih memperihatinkan, hal tersebut yang membuatkan beliau tergerak untuk mendirikan sebuah lembaga sosial yang bisa menganyomi sesama muslim terkhusus asli masyarakat muslim papua.

Suryo (2010) dalam mengelola panti asuhan, pimpinan panti asuhan dituntut untuk memimpin panti asuhannya dengan pola kepemimpinan yang bisa mudah sinergi dengan tenaga pendidik dip anti asuhan dan peserta didik dipanti asuhan tersebut. Pola kepemimpinan transformatif yang dipegang pengelola panti asuhan dalam memimpin panti asuhan, sebagaimana yang dilakukan pengelola panti asuhan kota tomohon, Minahasa. Sejalan dengan pendapat Kim (2014) dalam pola kepemimpinan transformatif dituntut adanya pengorganisasian wewenang yang merata diantara setiap orang dalam sebuah lembaga. Sebagaimana dalam dunia bisnis ataupun sosial komitmen yang tinggi dalam upaya pencapaian tujuan organisasi atau lembaga adalah sebuah prasarat mutlak guna kemudahan pencapaian tujuan lembaga tersebut. 
Panti asuhan putera puteri Papua muslim sebagai panti asuhan mandiri, karena sumber pembiayaannya tidak memiliki donator tetap, me lainkan dengan menjalankan beberapa usaha dalam pemenuhan kehidupan sehari - hari maupun kebutuhan sekolah mengingat biaya sekolah yang dibayar anak- anak panti 50\% dari lembaga dan 50\% dibebaskan dari sekolah, adapun sekolah yang menjadi pendidikan formal yaitu perguruan Muhammadiyah Kabupaten. Pengasuh memaparkan bahwa anak- anak panti setiap hari disela kesibukan sekolah juga beternak sapi, ayam, berkebun dan juga menjalankan bisnis pencucian motor dan mobil, dari situlah sumber dana tetap yang bisa membantu meringankan kebutuhan anak - anak panti asuhan putera puteri muslim papua, ditambah bantuan beras dalam program RASKIN setiap bulannya dari Dinas Sosial Kabupaten Sorong.

Hamidah memaparkan bahwa tidak semua anak dipanti asuhan adalah mereka yang yatim atau yatim piatu melainkan dari keluarga kurang mampu dan dari keluarga muallaf yang ingin menitipkan anak mereka sehingga dapat dibina dan diberi penguatan akidah, dua contoh diantaranya ialah Syamsiah Yenjoy dan Siti Sarah Yeblow yang kini sedang menyelesaikan perkuliahan di perguruan tinggi. Panti asuhan putera puteri papua muslim yang saat ini dipimpin oleh Ahmad Ronitanoi adalah suku daerah anak - anak panti kesemuanya berasal dari papua.

Kepedulian dan kepekaan umat Islam tentu pengaruhnya sangat besar terhadap regenerasi muslim papua, dipanti asuhan putera puteri papua muslim, dua orang diantaranya adalah dari keluarga muallaf dan sebagian besar mereka dari keluarga yang sangat minim ilmu pengetahuan dan pengamalan ajaran Islam, Sehingga masih butuh pembinaan, pada ke nyataannya pun dengan melihat pada keadaan 
sekitar, muslim orang asli papua kehidupan ekonominya belum mapan, sebagai contoh nyata di kompleks Kokoda, dan kampung muallaf bendungan SP 1. Umat Islam dituntut peduli dengan keadaan muslim asli orang Papua, Abdul Munyasih, sebagai contoh nyata yang sangat peka terhadap sesama muslim, beliau asli jawa datang ke Kabupaten Sorong sebagai peserta transmigran, bersama Yayasan Almuhajirin mendirikan lembaga khusus untuk menampung sekaligus membina anak - anak muslim Papua untuk mendapatkan kehidupan yang lebih baik seperti pada anak-anak umumnya.

Adapun jumlah anak - anak panti asuhan putera puteri papua muslim adalah 45 anak, terdiri dari 22 perempuan dan 23 laki - laki, mereka semua adalah orang asli papua dengan suku yang beragam, terbanyak dari mereka berasal dari daerah Bintuni dan Sausapor. Panti asuhan putera puteri Papua muslim sebagai lembaga sosial yang berfungsi pula sebagai madrasah pengganti pendidikan orang tua dan keluarga yang belum mampu diberikan oleh orang tua anak asuh. Hal ini menunjukkan ada kesulitan tertentu dalam mendapatkan pendidikan agama bagi keluarga muslim terutama dipelosok dan pulau-pulau.

\section{PEMBINAAN PENDIDIKAN ISLAM DI PANTI ASUHAN PUTERA PUTERI PAPUA MUSLIM}

Pamungkas (2016) mengemukakan bahwa Muslim Papua, sebagaimana direpresentasikan oleh Majelis Muslim Papua (MMP) telah mengonstruksikan identitasnya dalam ranah keagamaan Islam di Tanah Papua melalui tiga cara. Pertama, mengonstruksi diskursus Islam Rahmatan li Papua untuk meng-counter diskursus Islam rahmatan lil Alamin. Kedua, ikut berpartisipasi dalam upaya-upaya memperjuangkan hak-hak dasar orang Papua terutama HAM orang 
asli Papua. Ketiga, mengorientasikan perjuangannya dalam kerangka mewujudkan Papua sebagai tanah damai.

Sementara Sahara (2012) menguraikan latar belakang pendirian panti asuhan sangat beragam, secara umum latar belakang berdirinya panti asuhan adalah untuk memberikan pengasuhan dan pendidikan keislaman pada anak-anak yang membutuhkan. lebih dari sekedar lembaga pendidikan yang bertugas untuk mendidik generasi islam, pendirian pesantren juga sebagai ujung tombak dalam mendakwahkan Islam pada orang non Muslim dan memberikan pendidikan keislaman pada orang yang baru memeluk agama islam atau mualaf. Sebagaimana yang dilakukan oleh da'i dan pesantren di wilayah papua.

Adapun Ali dan Daud (1995) mengemukakan pendidikan yang ditanamkan dipanti asuhan adalah pendidikan akhlak dan pendidikan keagamaan. Sebagaimana halnya pendidikan keagamaan yang ditanamkan dipanti asuhan seperti solat, puasa, mengaji, dan sebagainya, pendidikan akhlak pun ditanamkan didalam panti serta mengembangkan ajaran akhlak yang terdapat dalam Alquran dan Assunnah itu agar manusia (muslim) dapat bersikap, berbudi pekerti dan bertingkah laku seperti yang ditetapkan dalam kedua sumber ajaran Islam tersebut.

Sebagaimana dipaparkan Harta (2016) bahwa orientasi pengajaran agama Islam selama ini lebih berorientasi pada peningkatan kesalehan pribadi, sedangkan orientasi kekinian seperti kesadaran menghargai pluralitas, Hak Asasi Manusia (HAM), nasionalisme, inklusivisme, dan lain sebagainya masih kurang mendapat perhatian. Kurikulum Pendidikan Islam dapat dikembangkan dengan menerapkan nilai-nilai pendidikan pluralitas di dalamnya pada mata pelajaran Alquran dan hadis, fikih, 
akidah-akhlak, dan Sejarah Kebudayaan Islam. Orientasi materi ajar ini sudah mulai menjadi tujuan materi pembelajaran materi keislaman di pesantren (Wekke, 2016).

Pembinaan pendidikan Islam yang dimaksud dalam penelitian dipanti asuhan putera puteri papua muslim adalah bimbingan yang dilaku kan dalam upaya mendidik, memberikan ilmu pengetahuan agama, meberikan pemahaman sampai pada pengaplikasian dalam tindakan nyata mengenai ajaran agama Islam.

Mochtar (2012) menjelaskan bahwa bahan ajar dipesantren atau panti asuhan bersumber pada al-quran, hadis serta literatur kitab kuning. Kitab kuning menjadi bahan dan sumber ajar yang penting dalam proses pendidikan akhlak di panti asuhan atau pesantren. Hamidah, pengasuh panti asuhan menguraikan penjelasan "Sholat ber jamaah merupakan hal rutin yang wajib dilaksanakan anak asuh selama berada dipanti, hal ini dilakukan untuk kedisiplinan dan pembiasaan, ba'da ashar mengaji bersama, sistemnya yang telah Alquran mengajari yang masih iqra hal ini dimaksudkan agar anak asuh belajar menjadi pengajar, bimbingan agama akan dilanjutkan setelah setelah Isya yaitu mengaji bersama dan ada ceramah yang disampaikan baik dari pengasuh maupun orang dari luar panti yang terkadang mengisi ceramah dan memberikan penguatan tentang ajaran agama islam pada anak-anak panti karena setelah mengaji sore dilakukan anak asuh harus mengurusi kegiatan rutin mereka yaitu beternak dan berkebun.

Yunus (2013) mengemukakan pola pembinaan akhlak yang ada dipanti asuhan selain dari mendidik tentang ibadah, shalat dan membaca al-quran juga harus mendidik peserta suhnya tentang toleransi yang sangat dibutuhkan di tengah-tengah masyarakat yang sangat majemuk sebagaimana di papua khususnya. Memberikan 
pendidikan akhlak berkenaan dengan toleransi merupakan sebuah keharusan bagi para pengasuh dan penglola panti asuhan. Hal ini bertujuan untuk menciptakan hubungan keagamaan yang harmonis ditengah perbedaan.

Pembinaan pendidikan Islam yang dilakukan dipanti asuhan putra puteri papua muslim dalam tujuh pola. Pertama, pembiasaan, Anak- anak dipanti asuhan putera puteri papua muslim dibiasakan melaksanakan kegiatan yang bersifat belajar. hal ini perlu diterapkan pada anak asuh karena dianggap sebagai cara yang paling efektif dalam membentuk kepribadian muslim, misalnya mmbiasakan bangun pagi, maembiasakan anak asuh sholat berjamaah dimusholah, mengaji selesai sholat, juga kebiasaan puasa senin kamis, sholat dhuha dan sholat malam. Walker, Roberts, \& Kristjansson (2012) menggambarkan pola pembinaan melalui metode pembiasaan ini dipandang lebih mudah di implementasikan di lembaga pendidikan yang berbasis asrama seperti pondok pesantren, panti asuhan atau lembaga boarding school lainnya. Hal ini sejalan dengan pendapat dari Aeni (2011) yang menyatakan bahwa proses menanamkan disiplin pada anak melalui daily activity sangat cocok dan sesuai dengan ajaran islam.

Kedua, cerita, yaitu dengan mengisahkan peristiwa sejarah hidup manusia yang menyang kut ketaatannya atau kemungkaran dalam hidup terhadap perintah Allah SWT. Rohmah (2008) mengemukakan penjelasan dalam Kecerdasan Majemuk bahwa metode pengajaran melalui metode bercerita sangat diperlukan dalam proses pembelajaran pendidikan agama islam untuk anak usia sekolah dasar.

Ketiga, Keteladanan, keteladan menjadi faktor penting dalam upaya pembentkan kepribadian muslim anak asuh, pimpinan dan pengasuh sebagai tokoh sentral yang memegang peranan penting 
dalam upaya pembentukan kepribadian muslim anak asuh yang ditunjukkan dengan cara bertutur kata, tingkah laku, ketaatannta dalam ibadah, serta berpakaian dan lain sebagainya. Hal ini sejalan dengan penelitian Sylviyanah (2012) bahwa metode peneladanan adalah metode yang tepat dalam proses pembinaan akhlak bagi murid-murid atay peserta didik yang masih dalam usia anak-anak.

Selanjutnya, keempat, mengaji bersama, tidak serta merta selesai sholat anak asuh dibiarkan berdiri dan pergi meninggalkan musholah tetapi mengaji bersama, yang rutin dilakukan adalah ba'da ashar. Syarifuddin (2004) menjelaskan aktivitas mengaji bersama saangat penting dilakukan oleh anak-anak yang sedang belajar alquran. Hal ini dikarenakan pada saat mengaji bersama anak-anak akan terhidar dari perasaan bosan dan belajar bersosialisasi dengan teman sebayanya.

Kelima, nasehat, disela sela kegiatan TPA dan kajian ba'da sholat pengasuh memberikan nasehat nasehat tentang bagaimana bersikap sesuai ajaran agama Islam dan memberikan solusi pagi anak asuh yang dilihat mengalami sebuah permasalahan. Dalam menghadapi masa peralihan menuju dewasa, seorang remaja tentunya memerlukan dorongan dan semangat dari orang tuanya terutama disaat mereka mengalami kegagalan. Dalam hal ini pengasuhlah yang menggantikan peranan orang tua sebagai orang tua pengganti.

Keenam, Penghargaan atau reward, menawarkan hadiah pada anak asuh yang melaksanaan berbagai perintah atau mendapat prestasi dan meninggalkan segala hal yang dilarang oleh pengasuh. Terakhir, Hukuman, memberikan hukuman pada anak asuh yang melanggar aturan atau tidak melaksanakan kewajibannya. Dalam proses Pendidikan Akhlak metode reward dan punishment akan sangat efektif jika dilaksanakan karena akan menumbuhkan motivasi untuk berbuat sesuai 
dengan yang diajarkan dan menjauhi hal-hal yang dilarang dalam proses kehidupan (Akhwan, 2014).

Prabadewi \& Widiasavitri (2014) mengemukakan publikasi di panti asuhan di kota Denpasar, Bali, Indonesia dengan kesimpulan bahwa aspek yang menentukan prestasi anak anak didik di panti asuhan sangat dipengaruhi oleh motivasi dalam dirinya. Motivasi yang dimiliki anak-naka untuk menjadi orang yang berprestasi dan sukses akan membawa pengaruh yang positif pada prilaku dan pola belajar mereka di panti asuhan.

Kepercayaan Diri yang dimiliki oleh para Remaja Penghuni Panti Asuhan akan menentukan prilaku dan kondisi psikologis yang memberikan pengaruh yang signifikan pada pembentukan moral dan mental anak-anaka yang tinggal di panti asuhan. Oleh sebab itu sangat penting para pengasuh panti memberikan materi pelajaran dan pendidikan yang bisa menumbuhkan dan menjaga kepercayaan diri yang dimiliki oleh semua anak asuh.

Selain dari motivasi diri dan kepercayaan diri merupakan dua hal yang harus menjadi fokus pembinaan mental peserta didik yang tinggal di panti asuhan. Rasa empati adalah hal yang begitu penting untuk dimiliki oleh anak-anak yang tinggal dipanti asuhan. Perbedaan kepemilikan kepekaan dan empati yang dimiliki oleh anak-anak yang ada dipanti asuhan mengharuskan para pengajar atau pendidik dipanti asuhan memberikan materi pembelajaran yang bisa menumbuhkan rasa empati pada diri anak-anak.

Sangat sederhana sekali pembinaan pendidikan Islam yang dilakukan tetapi upaya tersebut diharapkan mampu menguatkan aqidah anak. Maka tujuan panti asuhan putera puteri papua papua muslim, bukan hanya sekedar tempat berlindung atau memenuhi kebutuhan fisik anak saja, tetapi lebih dari itu yaitu penguatan bekal 
dan pedoman hidup me nyangkut hubungan manusia dengan Allah SWT, manusia dengan manusia, dan lingkungannya sehingga ajaran agama benar- benar dihayati, dipahami serta diamalkan, sedangkan hasil yang diharapkan dari kegiatan pembinaan pendidikan Islam secara khusus adalah terciptnya kualitas keimanan, kesadaran dan ketaqwaan dan adanya usaha untuk meningkatkan amal dalam kehidupan sehari hari.

\section{KESIMPULAN}

Anak asuh yang semuanya adalah orang asli papua dari pelbagai suku dan daerah di sekitar kabupaten Sorong, tidak menjadikan panti asuhan putera puteri papua muslim sebagai tempat berlindung atau memenuhi kebutuhan fisik saja. Namun lebih dari itu, berfungsi sebagai tempat pembinaan pendidikan Islam, dimana anak asuh diberi pembinaan dibidang mental spiritual. Dengan tujuan agar anak mampu mengatasi kesulitannya sendiri, melalui dorongan dan kekuatan iman, yang kedua dibidang pembiasaan dengan tujuan agar anak asuh terbiasa melakukan pengamalan agama secara kontinyu dan menjadikannya sebagai kebutuhan.

\section{DAFTAR PUSTAKA}

Aeni, A. N. (2011). Menanamkan Disiplin Pada Anak Melalui Dairy Activity Menurut Ajaran Islam. Jurnal Pendidikan Agama IslamTa'lim, 9, 1-13.

Akhwan, M. (2014). Pendidikan Karakter: Konsep dan Implementasinya dalam Pembelajaran di Sekolah/Madrasah. El Tarbawi, 8(1), 61-67.

Ali, M. D., \& Daud, H. (1995). Lembaga-lembaga Islam di Indonesia. Jakarta: Raja Grafindo Persada.

Cintas, C., Gosse, B., \& Vatteville, E. (2013). Religious identity: a new dimension of HRM? A French view. Employee Relations, 35(6), 576-592.

Gosita, A. (1998). Masalah Perlindungan Anak. Jakarta: Akademiko Persido. 
Harta, M. (2016). Implementasi Pendidikan Plural Dalam Kurikulum Pendidikan Islam Pada Madrasah Aliyah. Jurnal Al-Qalam, 22 (2).

Hartati, L., \& Respati, W. S. (2012). Kompetensi interpersonal pada remaja yang tinggal di panti asuhan asrama dan yang tinggal di panti asuhan cottage. Jurnal Psikologi, 10 (02).

Irwin, J., \& Bradshaw, K. (2011). The ethics challenge: establishing an ethics ambassador network to help embed an ethical culture. Strategic HR Review, 10(4), 26-32.

Kim, S., J. (2014). Integration Strategy, Transformational Leadership and Organozational Commitment in Korea's Coorporat Split offs. Procedia - Social and Behavioral Sciences, 109, 1353 1364.

Kumalasari, F., \& Ahyani, L. N. (2012). Hubungan antara dukungan sosial dengan penyesuaian diri remaja di panti asuhan. Jurnal Psikologi: PITUTUR, 1 (1), 19-28.

McCormack, M., Brinkley-Rubinstein, L., \& L. Craven, K. (2014). Leadership religiosity: a critical analysis. Leadership \& Organization Development Journal, 35(7), 622-636.

Mochtar, Affandi. (2009). Kitab kuning \& tradisi akademik pesantren, Cet. 1. ed. Bekasi: Pustaka Isfahan.

Pamungkas, C. (2016). Muslim Papua dan Muslim Pendatang:Pertarungan Identitas Antara Ke-Indonesia-an dan Ke-Papua-an. Jurnal Kawistara. 6 (3), Desember: 249-264.

Prabadewi, K. D. L., \& Widiasavitri, P. N. (2014). Hubungan Konsep Diri Akademik dengan Motivasi Berprestasi pada Remaja Awal yang Tinggal di Panti Asuhan di Denpasar. Jurnal Psikologi Udayana. 1 (2).

Rohmah. (2008). Teori Kecerdasan Majemuk Howard Gardner dan Pengembangannya pada Metode Pembelajaran Pendidikan Agama Islam untuk Anak Usia Sekolah Dasar. Jurnal Pendidikan Agama Islam, 1.

Sahara. Pola Pembinaan Muallaf di Kota Jayapura. (2012). Jurnal AlQalam. 18 (2), Juli - Desember.

Suryo, B. D. (2010). Pengaruh Gaya Kepemimpinan Transformasional, Budaya Organisasi dan Inovasi terhadap Kinerja (Studi pada Panti Asuhan di Kota Tomohon dan Kabupaten Minahasa). Jurnal aplikasi manajemen universitas brawijawa. 8 (2).

Suryo, B. D. (2010). Pengaruh Gaya Kepemimpinan Transformasional, Budaya Organisasi dan Inovasi terhadap Kinerja (Studi pada Panti Asuhan di Kota Tomohon dan 
Kabupaten Minahasa). Jurnal Aplikasi Manajemen-Journal of Applied Management, 8 (2), 391-404.

Syarifuddin, A. (2004). Mendidik anak: membaca, menulis dan mencintai Al-Quran. Gema Insani.

Sylviyanah. (2012). Pembinaan Akhlak Mulia Pada Sekolah Dasar. Jurnal Tarbawi, 1 (3).

Walker, D. I., Roberts, M. P., Kristjánsson, K. (2015). Towards a new era of character education in theory and in practice. Educational Review, 67:1, 79-96.

Wekke, I. S. (2011). Pendidikan Islam dan Pemberdayaan Masyarakat (Tinjauan Pendidikan Vokasional Pesantren Roudhatul Khuffadz, Sorong). Jurnal Kajian Islam Interdisipliner Hermenia, 10(1), 23-53.

Wekke, I. S. (2012). Pembelajaran Dan Identitas Muslim Minoritas. Jurnal Ilmu Pendidikan Al-Rabwah, 6, 75-93.

Wekke, I. S. (2013). Masjid di Papua Barat: Tinjauan ekspresi keberagamaan minoritas Muslim dalam arsitektur. El-Harakah (Terakreditasi), 15 (2), 124-149.

Wekke, I. S. (2015). Sasi Masjid dan Adat: Praktik Konservasi Lingkungan Masyarakat Minoritas Muslim Raja Ampat Ismail Suardi Wekke. Al-Tahrir, 15(1), 1-20.

Wekke, I. S. (2015b). Tradisi Pesantren dalam Konstruksi Kurikulum Bahasa Arab di Lembaga Pendidikan Minoritas Muslim Papua Barat. KARSA: Jurnal Sosial dan Budaya Keislaman, 22 (1), 20-38.

Wekke, I. S. (2016). Pengembangan Kurikulum Pendidikan Agama Islam Muslim Minoritas: Pesantren Nurul Yaqin Papua Barat. Madrasah, 6(2), 26.

Wekke, I. S. (2017). Harmoni Sosial Dalam Keberagaman dan Keberagamaan Masyarakat Minoritas Muslim Papua Barat. Kalam, 10(2), 295-312.

Wekke, I. S., Siddin, S., \& Kasop, I. (2017). Pesantren, Madrasah, Sekolah, dan Panti Asuhan: Potret Lembaga Pendidikan Islam minoritas Muslim. At-Tajdid: Jurnal Ilmu Tarbiyah, 6 (1). 